\title{
Properties of cortical axons for energy efficient cortical action potentials
}

Yuguo $\mathrm{Yu}^{1,2}$

From Twenty First Annual Computational Neuroscience Meeting: CNS*2012

Decatur, GA, USA. 21-26 July 2012

Brains are extremely energy demanding. Recent studies [1] have demonstrated that AP generated in mammalian neurons are more energy efficient than squid giant axon [2]. In an companion study, we have showed that a warm body temperature is a critical factor responsible for the high efficient cortical action potentials in endotherm brain neurons than those in ectotherm neurons. In this study, we investigate that besides warm body temperature, what are the principal factors affecting energy cost in action potential generation. Since the a

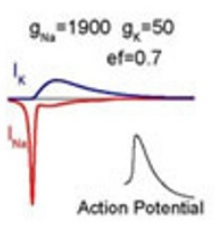

e

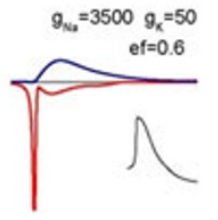

$\mathbf{f}$

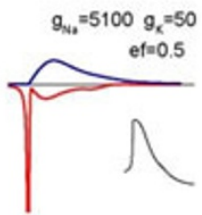

g

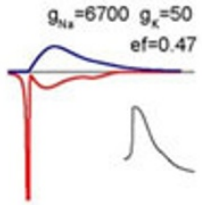

b
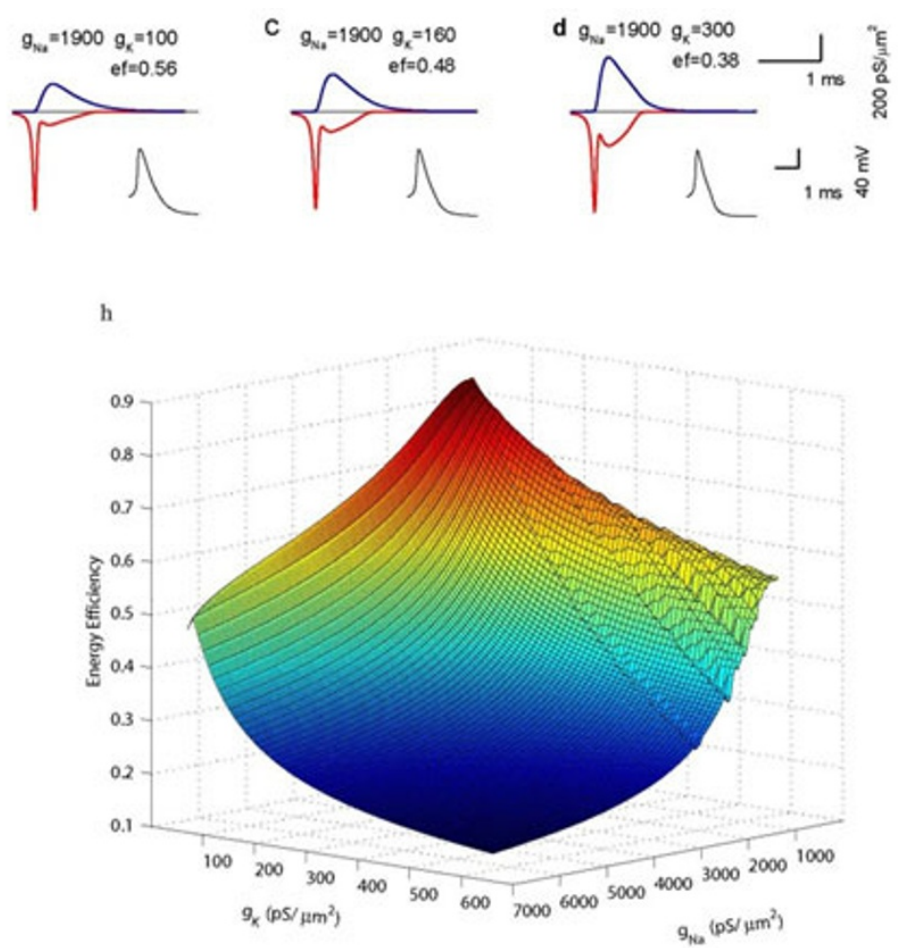

Figure 1 Spike energy efficiency is dominated by values of $\mathrm{Na}+$ and $\mathrm{K}+$ channel conductance.

Correspondence: yuyuguo@fudan.edu.cn

${ }^{1}$ Center for Computational Systems Biology, Fudan University, Shanghai,

200433, China

Full list of author information is available at the end of the article

(c) 2012 Yu; licensee BioMed Central Ltd. This is an Open Access article distributed under the terms of the Creative Commons 
energy cost is directly related to $\mathrm{Na}+$ and $\mathrm{K}+$ channels, we build up a cortical neuronal model based on Hodgkin-Huxley theory [3] and investigate the effect of changes in $\mathrm{Na}+$ and $\mathrm{K}+$ distribution density on the axon energetics. Figure 1 shows that there exist a pair of optimal $\mathrm{Na}+$ and $\mathrm{K}+$ conductance values, leading to the maximal energy efficiency. Below the level of the optimal $\mathrm{Na}+$ conductance, the action potential could not be generated, while above this level, the energy cost will increase gradually. For a fixed $\mathrm{Na}+$ conductance, a lower $\mathrm{K}+$ conductance results in an unstable spiking dynamics, and a higher $\mathrm{K}+$ conductance results in a high energy cost. Therefore, once a neuron developed a certain amount of $\mathrm{Na}+$ channel density, there exist an optimal $\mathrm{K}+$ channel density, where the spike dynamics is stable while the energy cost is minimized.

Then we studied the energy efficiency for action potential initiation and propagation in unmyelinated and myelinated axons. Comparing to a point model, $\mathrm{Na}+$ entry ratio (SER) increases for action potential initiation in the unmyelinated axon. This is because that an additional amount of $\mathrm{I}_{\mathrm{Na}}$ is required to flow into neighborhood axon compartment when AP is propagated on the axon. This axial $\mathrm{Na}+$ current results in a rapid rising phase of membrane potential, triggering a large amount of local $\mathrm{Na}+$ influx for local action potential generation. Therefore, this axial $\mathrm{Na}+$ current saves energy for action potential generation in the neighborhood compartment during AP propagation. Compared to the unmyelinated axon, spike propagation in a myelinated axon saves energy extensively for AP propagation.

In summing, the energy cost for action potential initiation and propagation in cortical axons is not only ionic channel dependent, but also axonal property dependent.

\footnotetext{
Author details

${ }^{1}$ Center for Computational Systems Biology, Fudan University, Shanghai, 200433, China. ${ }^{2}$ School of Life Sciences, Fudan University, Shanghai, 200433 China.
}

Published: 16 July 2012

\section{References}

1. Alle $\mathrm{H}$, Roth $\mathrm{A}$, Geiger JR: Energy-efficient action potentials in hippocampal mossy fibers. Science 2009, 325:1405-1408.

2. Hodgkin AL, Huxley AF: A quantitative description of membrane current and its application to conduction and excitation in nerve. J Physiol 1952, 117:500-44.

3. $Y u$ Y, Shu Y, McCormick DA: Cortical action potential backpropagation explains spike threshold variability and rapid-onset kinetics. J Neurosci 2008, 28(29):7260-7272.

doi:10.1186/1471-2202-13-S1-P6

Cite this article as: Yu: Properties of cortical axons for energy efficient cortical action potentials. BMC Neuroscience 2012 13(Suppl 1):P6.

\section{Submit your next manuscript to BioMed Central and take full advantage of:}

- Convenient online submission

- Thorough peer review

- No space constraints or color figure charges

- Immediate publication on acceptance

- Inclusion in PubMed, CAS, Scopus and Google Scholar

- Research which is freely available for redistribution

Submit your manuscript at www.biomedcentral.com/submit
C Biomed Central 